\title{
Analysis of Soil and Crop Properties for Precision Agriculture for Winter Wheat
}

\author{
E. Vrindts ${ }^{1}$; M. Reyniers ${ }^{1}$; P. Darius ${ }^{1}$; J. De baerdemaeker ${ }^{1}$; M. Gilot ${ }^{3}$; Y. Sadaoui ${ }^{3}$; M. Frankinet ${ }^{3}$; \\ B. Hanquet ${ }^{2}$; M.-F. Destain ${ }^{2}$ \\ ${ }^{1}$ Laboratorium voor Landbouwwerktuigkunde, Katholieke Universiteit Leuven, Kasteelpark 30, B-3001 Leuven, Belgium; e-mail of \\ corresponding author: els.vrindts@agr.kuleuven.ac.be \\ ${ }^{2}$ Laboratoire de Mécanique Agricole, Faculté Universitaire des Sciences Agronomiques de Gembloux, Passage des Déportés 2 , B-5030 \\ Gembloux, Belgium; e-mail: destain.mf@fsagx.ac.be
${ }^{3}$ Centre de Recherches Agronomiques de Gembloux, Ministère des Classes Moyennes et de l'Agriculture DG6, Département Production \\ Végétale, Rue du Bordia 4, B-5030 Gembloux, Belgium; e-mail: frankinet@cragx.fgov.be
}

(Received 1 July 2002; accepted in revised form 24 February 2003; published online 22 April 2003)

In a precision farming research project financed by the Belgian Ministry of Small Trade and Agriculture, the methods of precision agriculture are tested on grain fields with a view of implementation of precision agriculture methods in Belgian field agriculture. The project encompasses methods for automatic information gathering on soil and crop and analysis of this data for management of within-field variability. Automatic information capturing is combined with traditional data sources of soil sample analysis and crop observations. The measurements and part of the results on one particular field in Sauvenière are presented here. Five nitrogen management strategies were compared, but the resulting differences in nitrogen dose were small and did not lead to significantly different yield results. The yield results were correlated to topography-related variations in soil texture and chemical components and to crop reflectance measurements in May.

(C) 2003 Silsoe Research Institute. All rights reserved

Published by Elsevier Science Ltd

\section{Introduction}

Precision agriculture (PA) has many definitions but the following elements are generally included: the optimising of inputs, this means determining and applying locally adjusted inputs on the field, with the use of information technology. PA is technology enabled, and has provided tools for determining field variability and adjusting inputs to locally optimised values. Parts of the PA cycle exist, such as sensing and application techniques, but the PA system is not yet complete (Pierce \& Nowak, 1999; Robert, 1999). Pierce and Nowak (1999) claim that fields with high spatial variation and low temporal variation (for example variation in soil $\mathrm{pH}$ ) have the highest potential for PA. Temporal stability facilitates measurement and (decision on) variable rate applications. The agronomic and economic value of information on field variability and the effect of field variability on management are mostly still unknown. The National Research Council (1997) recognised the need to improve the understanding of the complex interactions between multiple factors affecting crop growth and farm decision making. Research on value of different data (soil parameters, topography, etc.) and correlations between yield and other information is necessary to answer these questions. A few studies have reported on a limited number of yielddetermining factors that are mostly inter-related (Sudduth et al., 1996). Heermann et al. (2002) conducted a more extensive research, including 30 different parameters on soil, crop, weeds and pests. Success in PA is related to how well it can be applied to assess, manage and evaluate the space-time continuum in crop production (Pierce \& Nowak, 1999) or put differently: success of PA management depends on whether or not the growth limiting factors can be determined and their effect estimated and managed. Many farmers try to limit risk in their management, and this must be taken into consideration when proposing PA strategies. If PA methods increase risk, farmers will probably not take them up. If on the other hand, the farmers feel comfortable with the information provided, it will 
change their management strategy. The farmers involved in an irrigation precision farming experiment (Heermann et al., 2002) changed their irrigation mana gement to decrease excess water and are willing to use reduced nitrogen doses, since the experiment showed that water and nitrogen were applied in excess of crop requirements. Confronted with the yield reduction because of non-uniformity in irrigation, one of the farmers made plans to improve the uniformity of irrigation.

One precision farming approach has been to define 'uniform' zones that can be managed with the same strategy (the same soil treatment, seed density, fertiliser dose, crop protection). The difficulty lies in the definition of the uniform management zones, because boundaries can change over time and for different field operations. It is a question if the current insight in agronomy is sufficient to effectively deal with spatial and temporal variation for example in nitrogen availability to plants.

In a precision farming research project financed by the Belgian Ministry of Small Trade and Agriculture, the methods of PA are tested on grain fields with a view of implementation of PA methods in Belgian field agriculture. The project encompasses methods for automatic information gathering on soil and crop and analysis of this data to get information on within-field variability that is relevant for field management. One of the objectives of the project is to develop experimentation methods that farmers can use for collecting field- or area-specific response curves with precision farming techniques (yield monitoring and variable fertiliser management) to adjust their management of field variation. The measurements and results on one particular field in Sauveniere are presented here. A number of information sources are used to gather information on crop, soil and yield. Traditionally, soil properties are determined by analysis of mixed samples, possibly complemented with soil maps or aerial photographs to guide sampling. The relatively new technique of measuring apparent soil electromagnetic conductivity (ECa) was used as additional information source in combination with chemical and textural analysis of soil samples taken in a $25 \mathrm{~m}$ by $25 \mathrm{~m}$ grid. Soil electrical conductivity is known to be determined by soil porosity, soil moisture content, concentration of dissolved electrolytes in the contained water, temperature and phase state of the pore water and the amount and composition of colloids (McNeill, 1980a). The grain crop was monitored with a number of optical sensing techniques, including image processing, line-imaging spectrography and radiometry. The different collected data layers combined are expected to give better insight to temporal and spatial variation in the field, enabling an optimal use of inputs.
Currently, only nitrogen fertiliser is considered for precision application in the project. Five different methods to determine optimal nitrogen dose were compared in a strip-plot design. In precision nitrogen management, the nitrogen fertiliser dose should be adjusted to the target crop development, taking local crop potential into account. Crop development may be limited by factors other than fertiliser availability. Only when there is enough information on field properties, the local optimal nitrogen fertiliser can be given, that is: no overdose and no shortage for the potential crop growth. Current methods of determining nitrogen fertiliser dose are often based on measurement of soil nitrogen and estimation of total need of the crop, taking into account the mineralisation, estimated with organic matter content of the soil. This is an estimation beforehand. Another approach uses crop features measured during the season to adjust fertiliser dose (Wollring et al., 1998), for example, the Hydro Precision N-tester, a hand-held device, and the Hydro PrecisioN Sensor, a tractor-mounted sensor and remote sensing. Remote sensing for nitrogen management is usually based on comparison to an area on the field with sufficient nitrogen, using the nitrogen reflection index (NRI) (Schleicher et al., 2001) or related indices (Stone et al., 1996) to determine a suitable nitrogen dose for every location on the field. The NRI is the ratio of the near infrared (NIR) reflectance less the green reflectance to the sum of NIR and green reflectance. Welsh et al. (1999) tested nitrogen treatments based on shoot density and historic yield. The strategies were higher dose on areas with low historic yield and lower dose on highyielding areas and the opposite strategy (high dose on high-yielding areas and low dose on low-yielding areas). For shoot density, the same strategies were tested. The historic yield approach did not lead to significant economic or agronomic benefits, as was also found by Haahr et al. (1999). Possible explanations are that yield can vary significantly from year to year and historic yield is not necessarily a good predictor of yield potential in the next season (Moore, 1998; Taylor et al., 2001). The shoot density approach, using measurements within the season, gave rise to increased yield when applying higher nitrogen dose on areas with low shoot density (Welsh et al., 1999). The withinseason evaluation of crop growth was a better basis for nitrogen management. The Home Grown Cereals Authority (HGCA) promotes the use of canopy development benchmarks for adjusting nitrogen management (Godwin et al., 2001).

Field experiments with precision farming techniques were set up to compare the performance of soil-based and crop-reflection-based methods to determine nitrogen dose. The AZOBIL method (Machet \& Dubrulle, 
1990, Meynard et al., 1997) is based on soil nitrogen content and soil texture parameters and was compared to using crop canopy properties to adjust the second and third nitrogen applications.

In short, the objectives for the presented research are:

(1) to study the correlation between soil and crop parameters and yield results, and to determine growth limiting factors on the field and

(2) to compare soil-based and crop-reflection-based methods of determining optimal nitrogen application for winter wheat.

\section{Methods}

\subsection{Description of the field}

The field where this experiment was set up is located near Gembloux (Belgium) and its surface is approximately $7 \mathrm{ha}$. The field is situated to the west of the Belgian 'silty area'. Fig. 1 shows the topography and soil maps of the experimental field. The central part of the field presents higher elevations than the northwestern and southern borders. The soil map reveals the presence of alluvial soils (light zones-Abp, in the Belgian classification) along these borders. The rest of the zone is covered by deep silty soils (Aba and AbB).

Soil properties, crop reflection and yield were measured during the 2001 season on the field with winter wheat, variety: Dekan. The normal crop protection measures were taken: herbicide treatment on 2 April, combined herbicide, stem growth reduction and fungicide treatment on 7 May, and two more fungicide treatments on 18 and 21 May. Nitrogen fertiliser was applied in three fractions on 30 March, 1 May and 21 May. The field was harvested on 15 August.

Plots were set up to compare five different methods to determine optimal nitrogen dose. The plots have dimensions of $9 \mathrm{~m}$ by $30 \mathrm{~m}$. Five methods were tested in long strips across the field (see Fig. 2). The first nitrogen application of $44 \mathrm{~kg} \mathrm{ha}^{-1}$ was applied uniformly over the field. The different treatments are:

(1) uniform nitrogen fertiliser application, dose determined by the AZOBIL method based on average field texture and nitrogen content, the applied fractions being 44, 66 and $75 \mathrm{~kg}$ nitrogen ha ${ }^{-1}$, total $185 \mathrm{~kg} \mathrm{ha}^{-1}$

(2) dose per plot, second fraction of $66 \mathrm{~kg} \mathrm{ha}^{-1}$, third fraction based on the Hydro sensor measurement;

(3) dose per plot, second and third fractions based on the Hydro sensor measurement;

(4) dose per plot, determined by the AZOBIL method based on the average soil nitrogen content and local texture and organic matter properties and

(5) dose per plot, determined by the AZOBIL method based on the local soil nitrogen content and local texture and organic matter properties.

The Hydro sensor recommendations are based on comparison to a reference plot that was measured before the Hydro sensor measurements. As reference plot, a
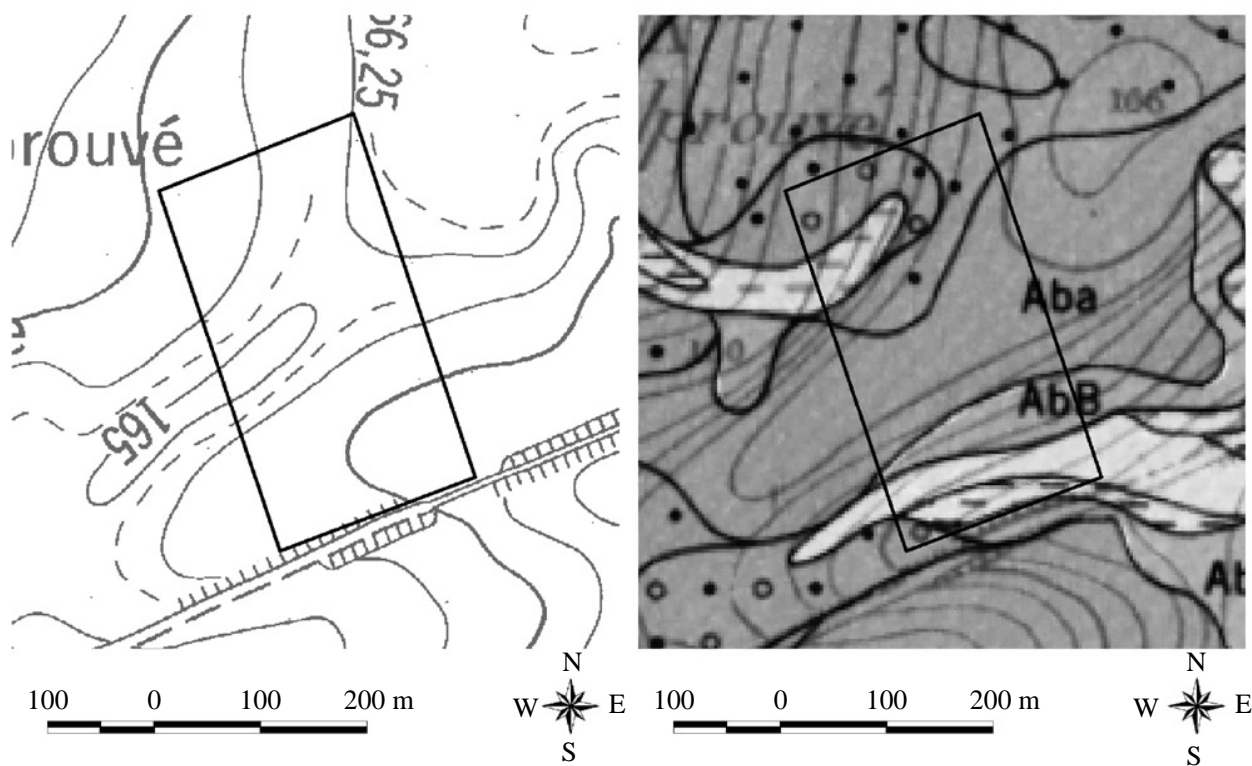

Fig. 1. Experimental field, topographic and pedological maps 


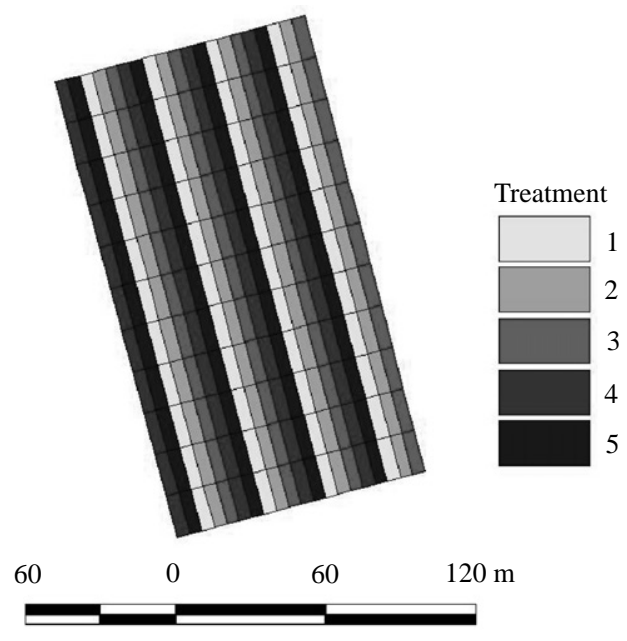

Fig. 2. Plot layout of winter wheat field, 2001, Sauveniere, with five nitrogen management treatments; description of treatments in text

part of the field with good crop growth was taken, from plots with treatment 1 and 2. The Hydro sensor recommendations were allowed to vary $40 \mathrm{~kg} \mathrm{ha}^{-1}$ plus or minus the dose for the uniform treatment (66 and $75 \mathrm{~kg} \mathrm{ha}^{-1}$ for the second and third fractions).

\subsection{Soil Texture and chemical analysis}

A traditional analysis of soil texture and chemical properties was performed on 12 February 2001, directed by Centre de Recherches Agronomiques de Gembloux. Samples of the top $0.30 \mathrm{~m}$ were taken in a $25 \mathrm{~m}$ by $25 \mathrm{~m}$ grid over the field. Among the measured parameters are: volumetric percentage of different texture classes, chemical components sodium $(\mathrm{Na})$, potassium $(\mathrm{K})$, calcium $(\mathrm{Ca})$, magnesium $(\mathrm{Mg})$, and plant available phosphate in $\mathrm{mg}$ per $100 \mathrm{~g}$ soil, organic matter content (mass percentage), acidity $(\mathrm{pH})$ and total nitrogen in $\mathrm{kg} \mathrm{ha}^{-1}$, determined with Kjeldahl method for inorganic nitrogen. The size distribution of the textural classes is as follows: clay, $<2 \mu \mathrm{m}$; fine silt, $2-20 \mu \mathrm{m}$; coarse silt, 20-50 $\mu \mathrm{m}$; fine sand, $50-200 \mu \mathrm{m}$ and coarse sand, $200 \mu \mathrm{m}-2 \mathrm{~mm}$.

\subsection{Soil electrical conductivity measurements}

The sensor that was used is the Geonics EM38 (Geonics Limited, Ontario, Canada). This sensor uses the electromagnetic induction technique (McNeill, 1980b). The soil apparent electrical conductivity (ECa) sensing method can be used in the field, without any perturbation and without taking soil samples. The
EM38 can be operated in two different modes: in vertical or in horizontal dipole position. Each mode results in a different investigation depth: the soil depth on which the electrical conductivity measurement is integrated is approximately $1.5 \mathrm{~m}$ in vertical mode $(\mathrm{ECV})$, while in horizontal mode $(\mathrm{ECH})$, the working depth is about $0.75 \mathrm{~m}$.

In order to do on-line field measurements, the Geonics EM38 is mounted on a specially constructed, tractor-pulled cart. The cart is entirely made of wood in order to avoid interference that would arise from metallic parts close to the sensor. Moreover, the design of the cart ensures a constant height of the sensor above the soil during operation and the possibility of doing measurements in both modes of operation (vertical ECV and horizontal ECH). The differential global positioning system (DGPS) localisation (Omnistar 3100-LR-12) guarantees an accurate localisation of EM38 measurements. The combined acquisition of the signals (EM38 and DGPS) was made by means of a LabView (National Instruments) self-made virtual instrument.

The first ECa measurements on the 5th of April were done without the cart. An operator carried the sensor along tracks in the field. Therefore, these data are less accurate than those acquired with the cart on 11th of September (better localisation and constant sensor height). On both dates, measurements were done in vertical mode.

Concurrently with ECa measurements, soil sampling was done in order to determine soil water content in 12 points. On the 5th of April, measurements were done on the top $0.30 \mathrm{~m}$ layer. On the 11 th of September, measurements were done on four layers: $0-0 \cdot 25,0.25-$ $0.50,0.50-0.75$ and $0.75-1 \mathrm{~m}$.

\subsection{Optical crop measurements}

Crop growth was measured with optical sensors on 3, 10 and 21 May, in different wavelength bands and at different spatial resolutions:

(a) crop and soil reflectance in five bands, blue, green, red, NIR $(850 \mathrm{~nm})$ and middle infrared (MIR, $1650 \mathrm{~nm}$ ) - measured with Cropscan radiometer MSR5 (CROPSCAN, Inc., VSA) in a circular field of view below the sensor with a diameter of approximately $0.7 \mathrm{~m}$; and

(b) crop reflection spectra from spectral line imagery, using IMSPECTOR V9 (Specim, Oulu, Finland) in combination with the DVC-10 Digiteyes (DVC COMPANY, VSA) digital camera, with National Instruments frame grabber 1411, using the analogue output of the camera (converted to 8-bit image), 
with high spatial resolution $\left(0.5 \times 10^{-4} \mathrm{~m}^{2}\right)$ and high spectral resolution $(7 \mathrm{~nm})$.

A Trimble AgGPS132 global positioning system (GPS) with real-time DGPS correction from Omnistar ensures correct localisation of the optical measurements (within $1 \mathrm{~m}$ in $\mathrm{XY}$ plane, within $2 \mathrm{~m}$ in $\mathrm{Z}$ direction, altitude being in meters above sea level). The optical instruments, GPS, a computer and power supply are mounted on a frame that can be attached to a tractor. The optical sensors are looking at an area behind and to the left of the tractor from a height of $1.5 \mathrm{~m}$ above the canopy. A Labview 6 (National Instruments) program was written for automatic data acquisition. The Cropscan measurements are taken every second, images are taken every $4 \mathrm{~s}$. The spectral images are processed in Labview 6 with IMAQ Machine vision and image processing tools to calculate the following parameters: crop cover and red edge inflection point (REIP). The crop cover was calculated as the number of plant spectra to the total number of spectra in the image. Plant and background spectra are classified automatically based on a normalised difference vegetation index (NDVI) threshold. The NDVI is defined in the following equation, where $I_{N D V}$ is the NDVI, $R_{750}$ is the NIR value at $750 \mathrm{~nm}$ and $R_{630}$ is the reflection value at $630 \mathrm{~nm}$ :

$$
I_{N D V}=\frac{\left(R_{750}-R_{630}\right)}{\left(R_{750}+R_{630}\right)}
$$

The wavelength of the REIP is a measure for chlorophyll absorption of a canopy and is located at higher wavelengths for higher chlorophyll absorption. The REIP is taken as the maximum of the firstderivative spectrum of plant spectra. Per spectral image, a mean value for REIP, the soil cover in per cent and the GPS coordinates are saved in a report file.

A number of indices were calculated based on the cropscan measurements, consisting of simple ratios of crop reflectance bands or NDVI or soil adjusted vegetation index (SAVI), which is defined as

$$
I_{S A V}=\frac{\left(R_{750}-R_{630}\right)(1+c)}{R_{750}+R_{630}+c}
$$

where: $I_{S A V}$ is the SAVI and $c$ is the soil cover as the ratio of area covered by plant divided by the soil area, expressed as a value between 0 (no plants) and 1 (soil fully covered by plants).

\subsection{Yield measurement}

The grain yield map was acquired with a New Holland combine harvester type CX820-A1, equipped with grain mass flow sensor, grain moisture sensor and a straw yield sensor (Maertens et al., 2000, 2002). The Precision Land Management Software of New Holland was used to read out the yield data. Pre-processing of yield data was according to the methods described in Reyniers et al. (2001).

\subsection{Geostatistical data processing}

All the data layers are analysed in ARCVIEW, ESRI geographical information system (GIS) and with standard statistical methods in SAS statistical software. Data analysis consists of a first quality check of the data in a GIS. Erroneous, extreme values are discovered by looking at histogram data and maps, and are deleted. For further analysis, data per $4 \mathrm{~m}$ grid were calculated for grain and straw yield and soil parameters with the nearest neighbour method, using four points, and an impact factor of 2. For interpolating differential GPS height data, the nearest neighbour method with 20 points and an impact factor of 2, was used. Analysis of the data layers included a general correlation analysis of all the parameters (soil texture and chemical composition, optical measurements and yield measurements). Yield prediction models based on soil and optical measurements were calculated and tested in SAS statistical software. Variable selection for grain yield prediction was based on a forward stepwise procedure (STEPDISC procedure in SAS). The overall yield results of the five nitrogen treatments were compared with an $F$-test on mean plot results. Using the mean results per plot has the advantage of having data that is independent and does not have the spatial structure of harvester data (high correlation along harvester lines, reduced correlation perpendicular to harvester driving direction). The five treatments were also compared within groups of five plots, allowing a local comparison with more or less the same soil type for the five treatments.

\section{Results and discussion}

The figures on field measurements were made in Arcview by interpolating to a $1 \mathrm{~m}$ grid, using inverse distance interpolation with $10 \mathrm{~m}$ radius and an impact factor of 2. Fig. 3 (a)-(f) shows results of soil measurements. The height in metres above sea level was taken from GPS readings. The soil texture parameters, clay and fine silt and associated elements (calcium and potassium), showed a pattern related to field topography. The same pattern is observed in the soil apparent electrical conductivity.

Comparing ECa maps and the pedological map (Figs 1 and 3), reveals the similarity of alluvial soils 

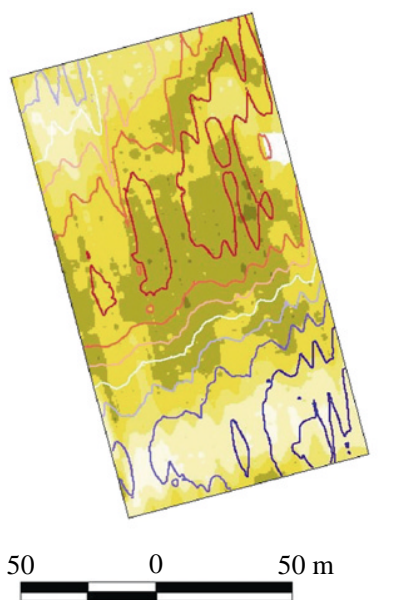

(a)
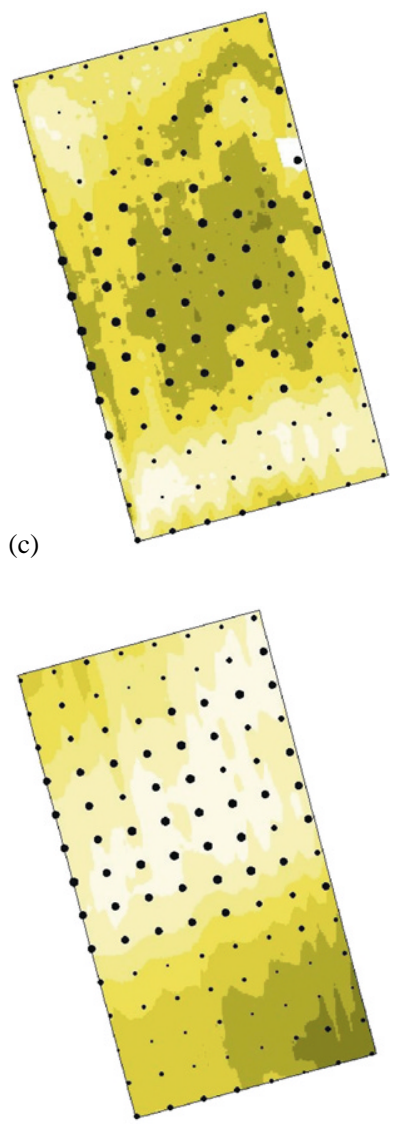

(e)
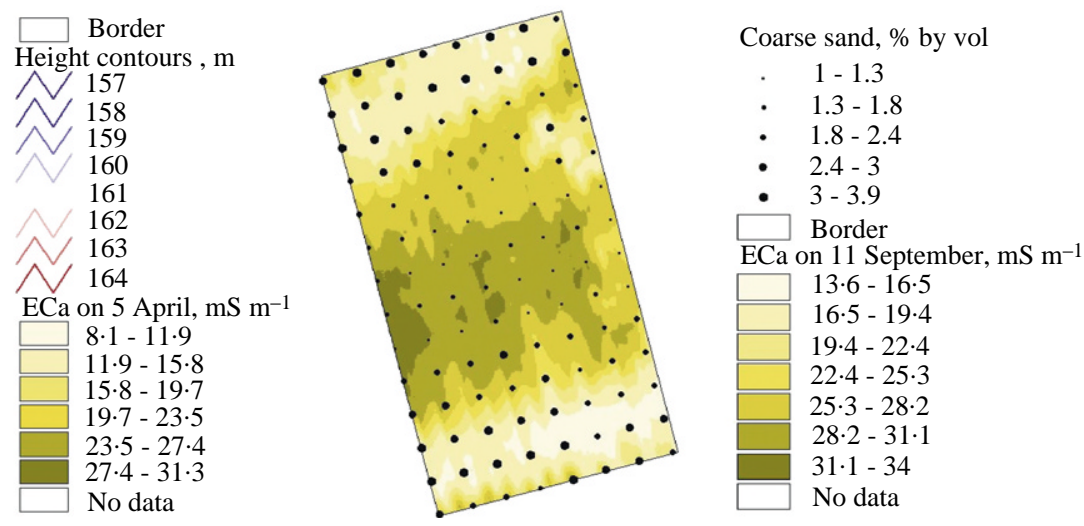

(b)

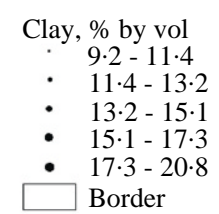

$\mathrm{ECa}$ on 5 April, $\mathrm{mS} \mathrm{m}^{-1}$

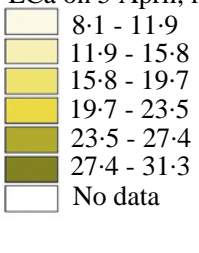

(d)

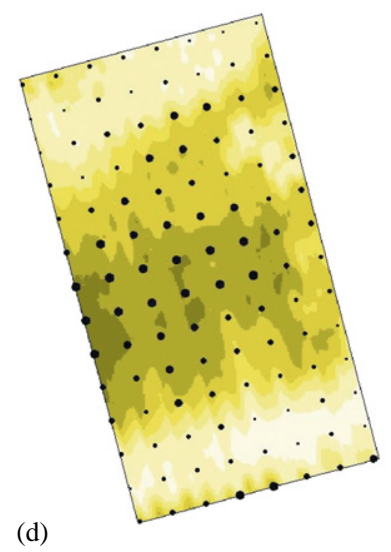

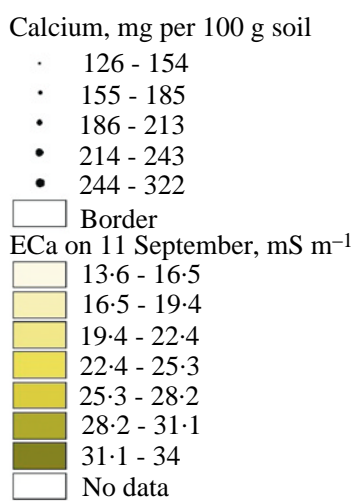

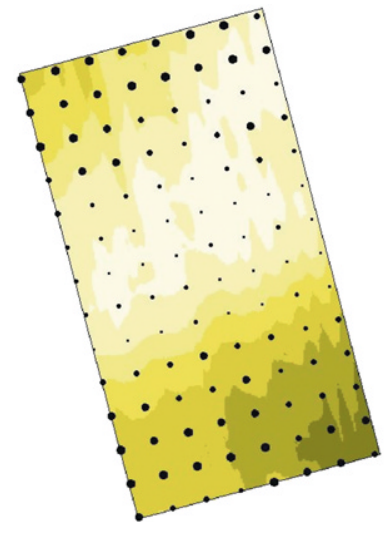
Coarse sand, $\%$ by vol$$
\text { - } 1-1.3
$$$$
\text { - } 1.3-1.8
$$$$
\text { - } 1.8-2.4
$$$$
\text { - } 2.4-3
$$$$
\text { - } \quad 3-3.9
$$$$
\square \text { Border }
$$$$
\text { Height, } \mathrm{m}
$$$$
155 \cdot 8 \text { - 157.1 }
$$$$
157 \cdot 1-158 \cdot 4
$$$$
158.4-159.8
$$$$
159 \cdot 8-161 \cdot 1
$$$$
161 \cdot 1-162 \cdot 4
$$$$
162 \cdot 4-163 \cdot 7
$$$$
163 \cdot 7-165 \cdot 1
$$

(f)

Fig. 3. Maps of soil textural and chemical parameters and apparent soil electrical conductivity (ECa): (a) soil ECa in $\mathrm{mSm}^{-1}$ on 5 April and height contours in metres above sea level; (b) coarse sand in volumetric per cent over soil ECa in $\mathrm{mSm}^{-1}$ on 11 September; (c) clay content in volumetric per cent over soil ECa on 5 April in $\mathrm{mS} \mathrm{m}^{-1}$; (d) calcium content in mg per $100 \mathrm{~g}$ soil over ECa on 11 September in $\mathrm{mSm}^{-1}$; (e) fine silt in volumetric per cent over height in $\mathrm{m}$; and $(f)$ coarse sand in volumetric per cent over height in $\mathrm{m}$

(Abp) and low ECa zones. These zones also show the lowest clay content (see Fig. 3). The ECa maps from April and September show similar patterns. The factor having the pre-dominant contribution in ECa is the clay content, and this parameter is not subject to quick and important modifications.

On the upper right corner, part of the field was flooded until June. There was almost no crop 


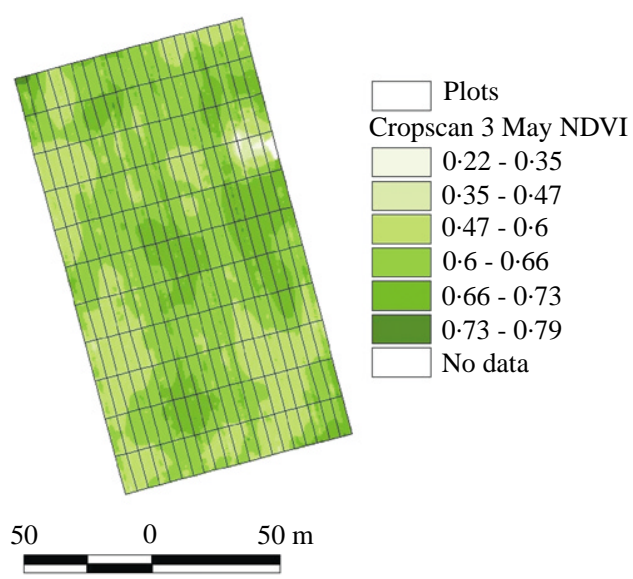

(a)

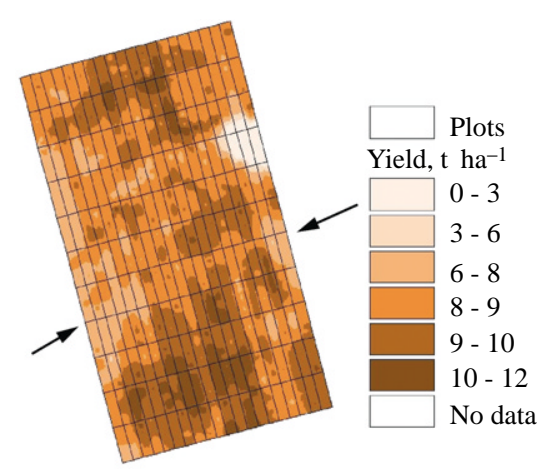

(c)

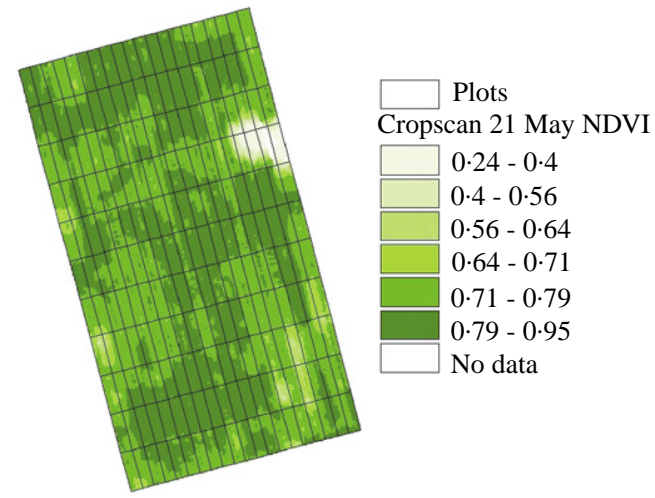

(b)

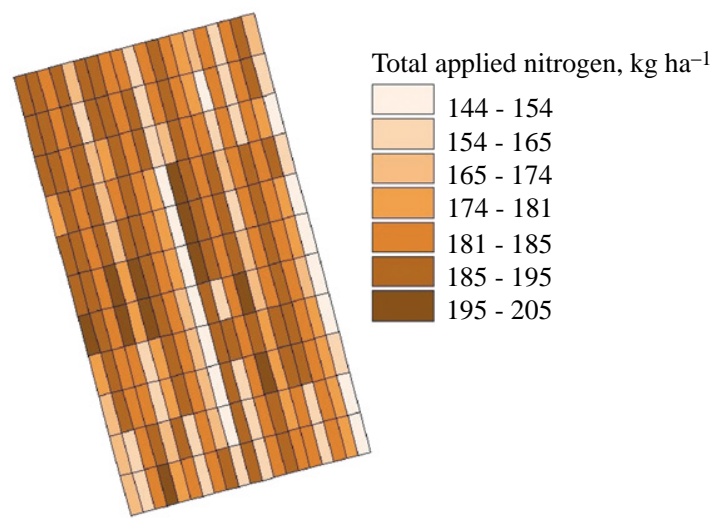

(d)

Fig. 4. (a) Crop normalised difference vegetation index (NDVI) on 5 May; (b) crop NDVI on 21 May; (c) yield in tha ${ }^{-1}$, arrows denote an area with lower yield and steep slope; (d) total applied nitrogen dose in $\mathrm{kg} \mathrm{ha}^{-1}$

development in this area. The flooded part of the field is clearly visible in the soil ECa measurements (part with low values) and optical crop measurements (see Fig. 4).

Crop reflection measured in May and yield (August) showed a similar pattern [see Fig. $4(b)$ and $(c)$ ]. The pattern in optical and yield measurements is no longer clearly related to topography or soil texture parameters. The applied nitrogen treatments did not lead to big differences in dose [Fig. 4(d)], so the crop reflection and yield did not show any fertiliser-induced differences. The yield does appear to decrease in the area with the steepest slope in the field [see arrows in Fig. 4(c)].

\subsection{Correlation between soil, crop and yield data layers}

All data layers were interpolated to a $4 \mathrm{~m}$ grid, resulting in 3713 points per data layer. In this correlation analysis, the data that belonged to a wet spot in the field (see light spot in Figs 3 and 4) were excluded, because they would distort the result. The correlation matrix for soil and yield data is given in
Table 1. Some of the soil texture parameters are correlated to height (see also Fig. 3), with coarser textures on lower areas. There are also higher correlations between soil textural parameters. Calcium $(\mathrm{Ca})$ and potassium $(\mathrm{K})$ are positively correlated to clay and fine silt content, while phosphate $\left(\mathrm{P}_{2} \mathrm{O}_{5}\right)$ is negatively correlated to clay and fine silt content. Phosphates are positively correlated to coarse silt and sand content. Calcium and potassium are negatively correlated to these texture parameters.

Grain and straw yield are correlated to each other and soil parameters soluble phosphate, coarse silt and sand, and negatively correlated to fine silt, clay and $\mathrm{K}$.

Table 2 gives the correlation of soil parameters to the soil EC on 5 April and optical parameters. As expected, the soil EC is highly correlated to texture parameters and chemical components. The correlation between grain yield and soil EC is $-0 \cdot 39$. Optical parameters on 3 and 21 May were faintly correlated to soil $\mathrm{pH}$ (coefficient of determination $R^{2}= \pm 0 \cdot 3$ ), except for the NIR bands and REIP (see Table 2). The NIR band and green/red ratio on 21 May showed a higher correlation 


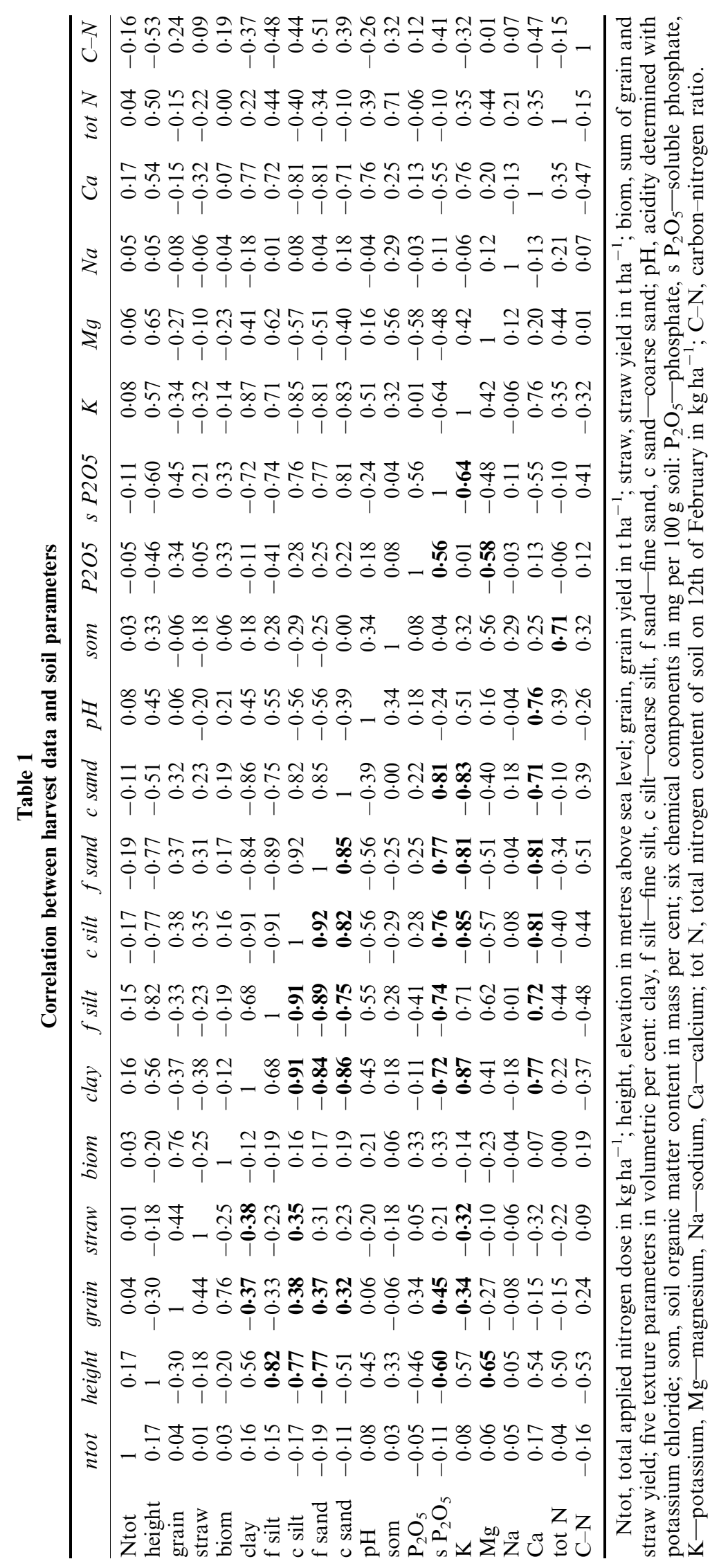




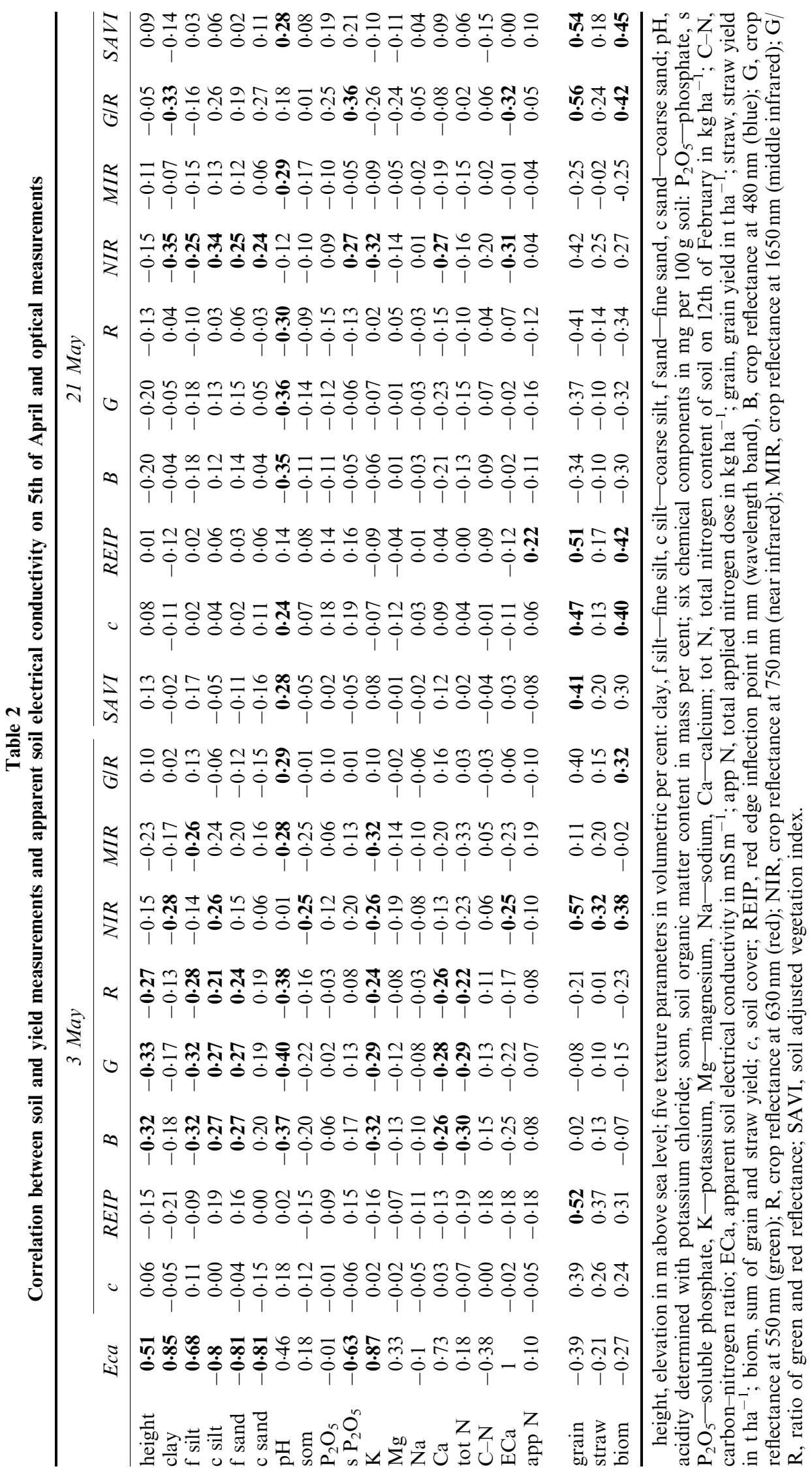


Table 3

Correlation between yield and optical parameters on 3 and 21 May, using a limited set of data

\begin{tabular}{|c|c|c|c|c|c|c|c|}
\hline 3 May & grain & straw & biomass & 21 May & grain & straw & biomass \\
\hline$c$ & $0 \cdot 39$ & $0 \cdot 35$ & $0 \cdot 17$ & $c$ & $0 \cdot 50$ & $0 \cdot 18$ & $0 \cdot 41$ \\
\hline REIP & 0.48 & 0.48 & 0.17 & REIP & 0.53 & 0.26 & 0.39 \\
\hline B & -0.04 & 0.05 & -0.08 & B & $-0 \cdot 36$ & -0.07 & $-0 \cdot 34$ \\
\hline G & $-0 \cdot 14$ & -0.02 & $-0 \cdot 14$ & G & -0.39 & -0.09 & $-0 \cdot 36$ \\
\hline $\mathrm{R}$ & $-0 \cdot 26$ & $-0 \cdot 13$ & $-0 \cdot 19$ & $\mathrm{R}$ & -0.42 & $-0 \cdot 13$ & $-0 \cdot 36$ \\
\hline NIR & 0.51 & 0.40 & $0 \cdot 25$ & NIR & 0.39 & 0.41 & $0 \cdot 12$ \\
\hline MIR & 0.03 & $0 \cdot 10$ & -0.04 & MIR & $-0 \cdot 33$ & -0.02 & $-0 \cdot 35$ \\
\hline $\mathrm{G} / \mathrm{R}$ & $0 \cdot 40$ & $0 \cdot 30$ & 0.22 & $\mathrm{G} / \mathrm{R}$ & 0.56 & $0 \cdot 28$ & 0.40 \\
\hline $\mathrm{NIR} / \mathrm{G}$ & $0 \cdot 33$ & $0 \cdot 20$ & $0 \cdot 21$ & $\mathrm{NIR} / \mathrm{G}$ & 0.49 & $0 \cdot 21$ & $0 \cdot 37$ \\
\hline NIR/R & $0 \cdot 34$ & 0.23 & $0 \cdot 20$ & NIR/R & 0.53 & $0 \cdot 25$ & $0 \cdot 39$ \\
\hline NIR/MIR & $0 \cdot 26$ & $0 \cdot 15$ & $0 \cdot 17$ & NIR/MIR & 0.53 & $0 \cdot 20$ & 0.42 \\
\hline $\mathrm{MIR} / \mathrm{G}$ & $0 \cdot 36$ & $0 \cdot 24$ & $0 \cdot 22$ & $\mathrm{MIR} / \mathrm{G}$ & $0 \cdot 22$ & $0 \cdot 12$ & $0 \cdot 15$ \\
\hline $\mathrm{MIR} / \mathrm{R}$ & $0 \cdot 42$ & $0 \cdot 30$ & 0.23 & $\mathrm{MIR} / \mathrm{R}$ & $0 \cdot 38$ & $0 \cdot 21$ & $0 \cdot 26$ \\
\hline NDVI & $0 \cdot 38$ & 0.23 & $0 \cdot 24$ & NDVI & 0.49 & $0 \cdot 20$ & $0 \cdot 38$ \\
\hline SAVI & 0.42 & $0 \cdot 32$ & $0 \cdot 22$ & SAVI & 0.54 & $0 \cdot 22$ & 0.43 \\
\hline
\end{tabular}

c, soil cover; REIP, red edge inflection point in $\mathrm{nm}$ (wavelength band), B, crop reflectance at $480 \mathrm{~nm}$ (blue); G, crop reflectance at $550 \mathrm{~nm}$ (green); R, crop reflectance at $630 \mathrm{~nm}$ (red); NIR, crop reflectance at $750 \mathrm{~nm}$ (near infrared); MIR, crop reflectance at $1650 \mathrm{~nm}$ (middle infrared); G/R, ratio of green and red reflectance; NIR/G, ratio of near infrared and green reflectance; NIR/R, ratio of near infrared and red reflectance; NIR/MIR, ratio of middle and near infrared reflectance; MIR/G, ratio of middle infrared and green reflectance; MIR/R, ratio of middle infrared and red reflectance; NDVI, normalized difference vegetation index; SAVI, soil adjusted vegetation index; grain, grain yield in $\mathrm{tha}^{-1}$; straw, staw yield in $\mathrm{tha}^{-1}$; biomass, sum of grain and straw yield.

to a number of soil parameters, but correlations remained below $0 \cdot 37$.

Correlation between yield and optical measurements is again given in Table 3. Since the optical measurements were not taken over all plots on both dates, a limited dataset was used for correlation calculation to yield, excluding areas that were not measured on one of the measurement dates. Among the optical parameters, grain yield is correlated best to REIP, the ratio of green and red reflectance, SAVI, and soil cover at both dates.

\subsection{Yield prediction based on soil and optical measurements}

For model predictions of the yield, the wet part of the field was excluded from the data. Stepwise selection of parameters to predict yield (procedure STEPDISC in SAS) showed again the higher correlation of grain yield to soil parameters soluble phosphate, followed by calcium, potassium, soil ECa and coarse sand. For prediction of straw yield, clay, coarse sand, potassium, phosphate and magnesium are the more important soil parameters.

Predicting yield with soil measurements (texture, chemical components and ECa of 5 April) and applied nitrogen, a maximum value for $R^{2}$ of 0.41 can be obtained for a regression model (using all parameters). The straw yield model had a maximum value for $R^{2}$ of
$0 \cdot 30$. Adding crop reflection parameters, the value for $R^{2}$ can be improved to 0.63 for grain yield prediction. A linear model for grain yield prediction based on the five parameters soluble phosphate, coarse silt, ratio of green and red reflectance on 21 May, SAVI on 21 May, and NIR reflectance on 3 May has a value for $R^{2}$ of 0.51 . The root mean square error for this model is $620 \mathrm{~kg} \mathrm{ha}^{-1}$, with a mean grain yield of $9350 \mathrm{~kg} \mathrm{ha}^{-1}$. Knowing the soil parameters that are (partly) determining the yield, these factors can be used to outline management zones for future crops. The applied nitrogen dose has very little effect on yield, because there were only small variations in the applied nitrogen dose [see Fig. 4(d)].

\subsection{Comparison of methods for nitrogen management in terms of yield}

Comparing the general result of the five treatments, there is very little difference in yield, with a slightly better result for the uniform treatment (see Table 4). The differences in yield are not significant on a 0.05 significance level. The nitrogen dose recommended by the Hydro sensor was on average lower than for other treatments.

The nitrogen treatments were also compared per group of five plots. The groups each contain five neighbouring plots with the five treatments. This was 
Table 4

Yield result and average nitrogen dose per treatment

\begin{tabular}{|c|c|c|}
\hline Treatment & $\begin{array}{c}\text { Average } \\
\text { yield, } \text { tha }^{-1}\end{array}$ & $\begin{array}{c}\text { Average } \\
\text { nitrogen } \\
\text { dose, } \\
\mathrm{kgha}^{-1}\end{array}$ \\
\hline (1) Uniform & 9.738 & 185 \\
\hline (2) Hydro sensor for third fraction & $9 \cdot 364$ & 187 \\
\hline $\begin{array}{l}\text { (3) Hydro sensor for second and } \\
\text { third fractions }\end{array}$ & $9 \cdot 148$ & 163 \\
\hline $\begin{array}{l}\text { (4) AZOBIL based on average soil } \\
\text { nitrogen content }\end{array}$ & $9 \cdot 254$ & 187 \\
\hline $\begin{array}{l}\text { (5) AZOBIL based on local soil } \\
\text { nitrogen content }\end{array}$ & $9 \cdot 299$ & 184 \\
\hline
\end{tabular}

done to have more or less the same soil conditions when comparing the nitrogen treatments. The yields were again not significantly different for most groups.

Looking at the ratio of yield to applied nitrogen dose, the Hydro sensor treatment (treatment 3 ) has the highest efficiency for nitrogen in terms of yield. The results of this analysis are affected by the fact that the yield variability is not strongly correlated with nitrogen dose.

Data from $1 \mathrm{y}$ are influenced by the specific climatic conditions of that year. The field is also monitored in 2002. This way, reoccurring, soil-related patterns in crop growth and yield can be discovered.

The results of any analysis on the data depend on the pre-processing and interpolation methods used. Data values for a certain place in the field can be different according to the interpolation method used, for example kriging with semi-variogram versus nearest neighbour interpolation (Moore, 1998). Furthermore, calculated correlations between variables can vary according to the grid size: a coarser grid may result in higher correlations, because there are less points in a coarser grid or because inaccuracies in measurement and localisation are evened out in a coarser grid. There is still lot of research necessary to determine the correct geostatistical procedures to (pre)process the data.

\section{Conclusions}

Different parameters of soil, crop and yield were measured on a field in Sauveniere, Belgium, to study correlation between soil and crop parameters and yield results, and to determine important factors for management of field variability. Soil texture showed some topography related variation over the field, and this had a small influence on the yield results: grain yield and texture parameters had a correlation of $0 \cdot 32-0 \cdot 38$. On the studied field in 2001, soluble phosphate was the most important soil parameter to predict grain yield (coeffi- cient of determination $R^{2}=0.45$ ). Crop reflection in May has good correlation to grain yield, especially near infrared reflectance $\left(R^{2}=0.51\right)$ on 3 May, and the soil adjusted vegetation index $\left(R^{2}=0.54\right)$ and the ratio of green to red reflectance $\left(R^{2}=0.56\right)$ on 21 May. A linear grain yield prediction model based on all soil and crop variables has a maximum value for $R^{2}$ of 0.63 , meaning that yield was also affected by factors that were not measured.

Soil-based and crop-reflection-based methods to determine optimal nitrogen application for winter wheat were compared, but the different methods did not lead to much difference in applied nitrogen or in yield results. The methods did not differ significantly for yield results. Lower nitrogen doses were applied based on crop reflection methods, and this method yielded the best nitrogen efficiency in terms of grain yield (highest ratio yield/applied nitrogen), but again, differences between treatments were not significant.

\section{Acknowledgements}

The Belgian Ministry of Small Trade and Agriculture is gratefully acknowledged for financial support of this research.

\section{References}

Godwin R J; Earl R; Taylor J C; Wood G A; Bradley R I; Welsch J P; Richards T; Blackmore B S; Carver M C; Knigth S; Welti B (2001). Precision Farming of Cereal Crops: a Five-year Experiment to Develop Management Guidelines. HGCA, London

Haahr V; Jørgensen R N; Jensen A; Overgaard J (1999). A method for optimal site-specific nitrogen fertilisation. In: Precision Agriculture '99-Proceedings of the second European Conference on Precision Agriculture (Stafford J V, ed), Nr. 2, pp 709-718. Society of Chemical Industry/ Sheffield Academic Press, Sheffield, UK

Heermann D F; Hoeting J; Thompson S E; Duke H R; Westfall D G; Buchleiter G W; Westra P; Peairs F B; Fleming K (2002). Interdisciplinary irrigated precision farming research. Precision Agriculture, 3(1), 47-61

Machet J-M; Dubrulle P (1990). Azobil: a computer program for fertilizer $\mathrm{N}$ recommendations based on a predictive balance sheet method. In: Proceedings of first congress of the European Society of Agronomy (Scaife A, ed), 5-7 December 1990, Paris. ESA, Colmar, France

Maertens K; De Baerdemaeker J; Reyns P; Missotten B (2000). On-line grain and straw yield measurements during harvest. In: Proceedings of 28th International Symposium on Agricultural Engineering, 1-4 February 2000, Opatija, Croatia, pp 25-32

Maertens K; Schoukens J; Deprez K; De Baerdemaeker J (2002). Development of a smart mass flow sensor based on adaptive notch filtering and frequency domain 
identification. American Control Conference, 8-10 May 2002, Anchorage, United States, pp 4359-4364

McNeill J D (1980a). Electrical conductivity of soils and rocks. Technical Note TN-5, Geonics Ltd, Mississauga, Ontario, Canada

McNeill J D (1980b). Electromagnetic terrain conductivity measurement at low induction numbers. Technical Note TN-6, Geonics Ltd, Mississauga, Ontario, Canada

Meynard J-M; Justes E; Machet J-M; Recous S (1997). Fertilisation azotée des cultures annuelles de plein champ [Nitrogen fertilisation of annual cultures in the field]. In: Maîtrise de l'azote dans les agrosystèmes. les Colloques de l'INRA 83 (Lemaire G; Nicolardot B, eds), pp 183-200. INRA, Paris, France

Moore M (1998). An investigation into the accuracy of yield maps and their subsequent use in crop management. Diss. Cranfield, Cranfield University, Silsoe College, Department of Agriculture and Biosystems Engineering

National Research Council (1997). Precision Agriculture in the 21st Century. Committee on Assessing Crop Yield: SiteSpecific Farming, Information Systems, and Research Opportunities. National Academy Press, Washington DC, pp 149

Pierce F J; Nowak P (1999). Aspects of precision agriculture. Advances in Agronomy, 67, 1-85

Robert P (1999). Precision agriculture: research needs and status in the USA. In: Precision Agriculture '99-Proceedings of Second European Conference on Precision Agriculture, nr. 1, pp 19-33. Sheffield Academic Press, Sheffield, UK

Reyniers M; Maertens K; Reyns P; De Baerdemaeker J (2001). Management of combine harvester precision farming data to make useful maps. In: Proceedings of the Third European
Conference on Precision Agriculture (3ECPA), nr. 1, 18-20 June 2001, Montpellier, France, pp 91-96

Schleicher T D; Bausch W C; Delgado J A; Ayers P D (2001). Evaluation and refinement of the nitrogen reflectance index (NRI) for site-specific fertilizer management. 2001 ASAE Annual International Meeting, St- Joseph, MI, USA. ASAE Paper No. 01-11151

Stone M L; Solie J B; Raun W R; Whitney R W; Taylor S L; Ringer J D (1996). Use of spectral radiance for correcting inseason fertilizer nitrogen deficiencies in winter wheat. Transactions of the ASAE, 39(5), 1623-1631

Sudduth K A; Drummond S T; Birrel S J; Kitchen N R (1996). Analysis of spatial factors influencing crop yield. In: Proceedings of the Third International Conference on Precision Agriculture Minneapolis, MN, USA (Robert P C; Rust R H; Larson W E, eds), Nr. 1, pp 129-140. ASA, CSSA, SSSA. Madison, WI, USA.

Taylor R K; Kluitenberg G J; Schrock M D; Zhang N; Schmidt J P; Havlin J L (2001). Using yield monitor data to determine spatial crop production potential. Transactions of the ASAE, 44(6), 1409-1414

Welsh J P; Wood G A; Godwin R J; Taylor J C; Earl R; Blackmore B S; Spoor G; Thomas G (1999). Developing strategies for spatially variable nitrogen application. In: Precision Agriculture '99-Proceedings of the second European Conference on Precision Agriculture (Stafford J V, ed.), nr. 2, pp 729-738. Society of Chemical Industry/ Sheffield Academic Press, Sheffield, UK

Wollring J; Reusch S; Karlsson C (1998). Variable nitrogen application based on crop sensing. In: Proceedings No. 423, Conference in Cambridge, UK, 10 December 1998. The International Fertiliser Society, York, UK 